\begin{tabular}{|l|l|l||}
\hline \multicolumn{2}{|c|}{ PublisherInfo } \\
\hline \hline PublisherName & $:$ & BioMed Central \\
\hline \hline PublisherLocation & $:$ & London \\
\hline \hline PublisherImprintName & $:$ & BioMed Central \\
\hline \hline
\end{tabular}

\title{
Self-regulated anti-inflammatory gene therapy
}

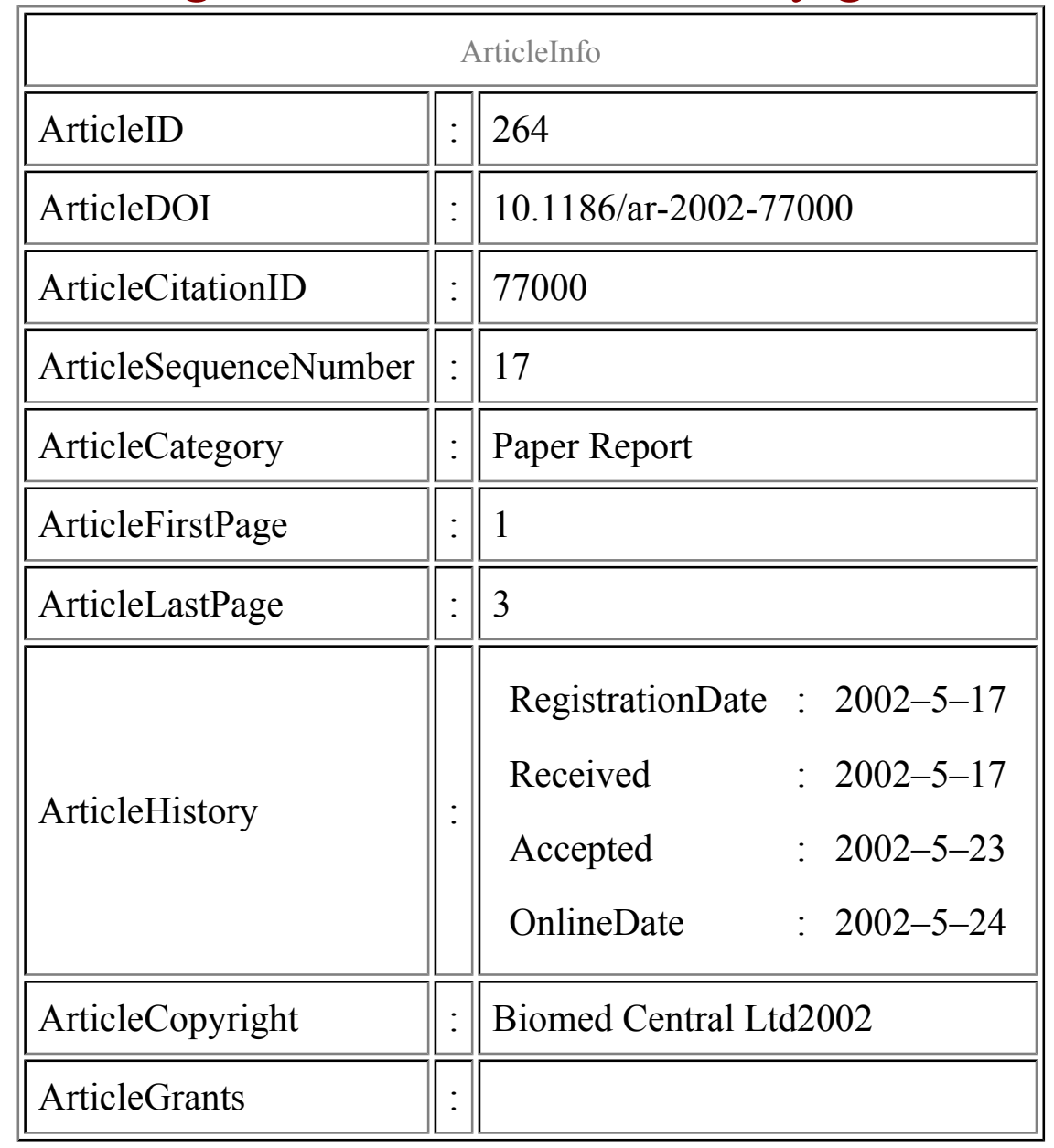




\begin{tabular}{|l|l|l|}
\hline ArticleContext & $:$ & 130754411 \\
\hline
\end{tabular}

\section{Cheryl Smythe, ${ }^{\text {Aff1 }}$}

Aff1 Imperial College Faculty of Medicine, London, UK

\section{Keywords}

adenovirus, gene transfer, IL-10, streptococcal cell wall arthritis

\section{Context}

Rheumatoid arthritis is associated with an imbalance of pro- and anti-inflammatory mediators. Adenoviral-mediated transfer of genes encoding therapeutic proteins has been shown to be effective at restoring homeostasis in animal models. However, the expression of therapeutic protein needs to match the cycles of inflammatory disease, as inappropriate expression of anti-inflammatory protein from the transgene may lead to immunosuppression and reduced efficacy of treatment. These authors have therefore developed an approach termed 'physiologically responsive gene therapy', whereby the antiinflammatory transgene is autonomously regulated by an inflammation-inducible promoter. Using this approach, the authors tested the capacity of adenoviral human IL-10 to maintain inflammatory homeostasis in the treatment of streptococcal cell wall (SCW) arthritis in rats.

\section{Significant findings}

The inflammation-inducible promoter consists of the complement factor 3 (C3) promoter, driving expression of the HIV Tat protein, and the HIV promoter, which is transactivated by Tat, driving expression of the transgene. Both promoters are also cytokine responsive. In order to examine the ability of the $\mathrm{C} 3$-tat/HIV promoter to respond to inflammatory mediators, primary synovial fibroblasts from arthritic rats were infected with a reporter adenovirus (Ad.C3-tat/HIV-luc). Low basal expression of the reporter gene was observed which could be induced 1000-fold with lipopolysaccharide, IL-1, IL-6 or TNF-a. When injected into primed ankle joints 2 days prior to the reactivation phase of SCW arthritis, a reporter gene driven by the $\mathrm{C} 3$-tat/HIV promoter showed low basal expression which was significantly induced following reactivation. Given that IL-10 has been previously shown to block NF?B activation, arthritic mice were injected with a human IL-10 (hIL-10) containing adenovirus (Ad.C3-tat/HIVhIL-10) to assess the therapeutic efficacy of inflammation-induced hIL-10 expression. Inflammationinducible hIL-10 gene transfer significantly inhibited joint swelling and leukocytosis. Levels of hIL-10 
elevated by reactivation returned to baseline within 2 days. Furthermore the level of hIL-10 induction was directly related to the severity of SCW arthritis.

\section{Comments}

This ingenious study demonstrates that self-regulated anti-inflammatory gene therapy is a feasible therapeutic approach. The general use of adenoviral-mediated gene therapy has remained questionable, as adenoviral vectors elicit their own immune response about 2 weeks after injection (animals were studied only up to 6 days in this study). However transgenic expression of IL-10 has previously been shown to reduce adenoviral-mediated inflammation (see additional information). Therefore, it would be of enormous interest to test the inflammation-inducible hIL-10 construct in a longer-term model of animal arthritis.

\section{Methods}

Adenoviral preparation, streptococcal cell wall arthritis model, western blotting

\section{Additional information}

Quattrocchi E, Dallman MJ, Dhillon AP, Quaglia A, Bagnato G, Feldmann M: Murine IL-10 gene transfer inhibits established collagen-induced arthritis and reduces adenovirus-mediated inflammatory responses in mouse liver. J Immunol 2001, 166:5970-5678 (Paper\%20report)

\section{References}

1. Miagkov AV, Varley AW, Munford RS, Makarov SS : Endogenous regulation of a therapeutic transgene restores homeostasis in arthritic joints. J Clin Invest. 2002, 109: 1223-1229.

This PDF file was created after publication. 